\title{
Managing Residential Density Development in Akure Through E-land Pricing System
}

\author{
Fasakin J.O. ${ }^{1} \quad$ Basorun J.O. ${ }^{1} \quad$ Bello M.O. $^{2} \quad$ Alese B.K. $^{3} \quad$ Enisan O.F. ${ }^{1} \quad$ Ojo B. $^{2} \quad$ Popoola O.O. $^{1}$ \\ 2016 TetFUND Research Group \\ 1.Department of Urban and Regional Planning, \\ 2.Department of Estate Management, \\ 3.Department of Computer Science \\ Federal University of Technology Akure, Nigeria
}

\begin{abstract}
One of the major challenges of Akure in the past two decades is the uncoordinated residential density development. This paper examined this haphazard development by mapping out the housing density mix in selected residential neighbourhoods in the city with a view to developing an e-land pricing model for its effective land management therein. The study identified three residential estates in Akure as representatives of the three broad densities (high, medium, low) in the residential zones using Geographic Information Systems (GIS). Primary data were generated from the administration of structured questionnaire that captured information on socio-economic characteristics of the respondents, location of buildings, plot sizes, coverage and prices among others. From the research findings, a high level of unregulated pricing was obvious particularly in the private sector that controls vast areas of the city land. The closer a private landed property to the city centre or a government housing scheme, the higher the price irrespective of the plot size. Sudden increase in income of residents is a determinant of the willingness to purchase land at high prices. To address this trend this study has developed an e-land pricing interface to regulate the residential density choice in the city. The model was tested to successfully predict specific areas for density development given certain variables such as regular income of land buyers, price of land, plot sizes among others. An administrative structure that can ensure management of the proposed e-land pricing reform measure was specified for effective density mix in the city.
\end{abstract}

Keywords: Residential, density development, housing, e-land pricing, Akure.

DOI: $10.7176 / \mathrm{JEES} / 9-7-04$

Publication date:July $31^{\text {st }} 2019$

\subsection{Introduction}

Housing densities are increasingly mixed in Nigeria due to the combination of many interrelated components which include; land price, infrastructure, building materials, policies, building regulations and more importantly, finance. Land in housing densities is very important because of the huge financial requirement and scarcity in most urban centres of the country for housing production (Mehmet, 2009). The difference in prices of land which ranges from one city to another, even in the same region/state, is of serious concern. Landowners in one city will tend to have lower expected present values of returns from future development than their more optimistic counterparts in another. Invariably, there are variations in landowner expectations within each of the cities. (Ebie, 2003). When the landowners compare their initial expectations regarding returns from current development with the anticipated returns from future development, the patterns of decisions will vary between cities.

Landowners in rapidly growing cities such as Lagos, Port-Harcourt, Kaduna and Akure will reserve more land for future development. The more growth they expect, the greater their tendency will be to sit tight and wait for higher returns on their land (Omole and Akinbamijo, 2012). The withholding of land decreases the supply available for current development at any distance from the center. This often moves the price of land up (Jaiyeoba and Amole, 2002) and causes some additional land to be released for current development.

E-land pricing for residential development entails the mapping out of various categories of density in the residential estates using Geographic Information System (GIS) and allocates land charges based on land location. It relies on encrypted digital signatures identifying the location of land with its associated price. Land prices vary directly with the level of expectation concerning future residential demand. Higher price for land prompts developers to use less land in the construction of housing, substituting other inputs for land (Oduwaye, 2009). Density of residential development on land that is developed (and not withheld) may vary directly with land prices concerning future residential demand. Ironically, a fast growing city like Akure, with more sprawls, calls for a pragmatic planning approach in its development. The traditional assumption of employment being concentrated in a single center has become less tenable with the decentralization of commercial and industrial activities in most large urban areas (Ilechukwu, 2010).

Research on e-land pricing is a means of ensuring proper density development in a residential estate. It is also an avenue to ensure orderliness with accurate planning standards that promote healthy environment for the inhabitants of the nation. The successful acceptance of e-land pricing will ensure that land administrators and 
policy makers have a livable environment. The kind and prices of housing produced, the population groups served, and the cost and problems of providing public services are all determined by the workings of the development process. An understanding of this process requires an examination of the relationships between land prices, location and density of development.

The quantity of land withheld from current development and the amount of urban sprawl vary directly with the levels of expectation concerning future residential demand (Williams, 2002). When expectations about future development potential are high, more land will be withheld from development, land values will be higher, and the densities in developed areas will be higher. More will be done on less land, at higher prices, as the owners wait for higher expected returns from future development. From the foregoing, land price is one of the factors inhibiting a good density development in Nigeria; yet, little or no attention is given to e-land pricing in urban development. This paper therefore, focuses on managing residential density development through e-land pricing system in Akure, Nigeria.

\subsection{Literature Review}

Residential housing sector plays a critical role in the development of an economy and it is one of the most important basic needs of man (Mehmet, 2009). It is an obligation for the government to provide affordable accommodation to its citizens irrespective of their location in the country. Currently many cannot afford a decent home in Nigeria as nearly half of its population lives in urban and semi-urban areas, with majority living in slums and substandard accommodation. However, Mabogunje (2002) has asserted that government had undertaken some significant steps in meeting the demand for housing. These efforts have very limited impact on the housing needs, especially for the low and middle income groups. Despite the significance of housing, adequate supply has remained a mirage to all cardres of the society in Nigeria. The situation is very peculiar to Akure where population grows at exponential rate with high discrepancy in housing need and supply.

Rising land prices and charges appear exorbitant and much above the official income capacity of average Nigerian citizen. Available data indicates that, the housing demand-supply gap for Nigeria is about 16 million units. In Akure, where most residents live in rented and sub-standard accommodation, market opportunities exist for thousands of quality homes (Lawanson, 2007). This makes it imperative for the development of mechanism for density mix development to ensure that vacuum created due to rising land price is filled.

In view of interrelated components of e-land pricing in residential housing, different scholars from schools of thought have expressed personal or group opinions on the term "affordable housing" (Agbola, 2004; Agbola and Olatubara, 2003; Aluko, 2010; Duncan, 2008). The views of these scholars vary depending on the aspect of housing each one delved into. Omirin (1998) studied the land accessibility and low-income house building in Metropolitan Lagos. Based on the analysis of house builders' behaviours of selected low-income earners of Lagos, it was discovered that it was a wrong notion to continue to rank land accessibility as the greatest constraint of house builders. Lack of finance and escalating cost of building materials and land now take precedence over land accessibility.

The adoption of e-land prices on density mix in residential estate in Nigeria is long overdue. Onibokun (1985) and Ebie (2003) observed that rent in major cities in Nigeria is about $60 \%$ of an average workers disposable income. This is on the high side considering the $20-30 \%$ recommendation by the United Nations. Strengthening cooperative housing system in the country, therefore, was suggested (Fasakin, 1998). In recognition of the fact that financial institution should be more accessible to the people (Omole, 2001), government most often finds ways to improve existing housing condition of the people through housing finance. However, what is required is systematic arrangement of housing densities to attain a sustainable urban system.

\subsection{Electronic models of land management in Nigeria and Ondo State}

Globally, agencies in advanced market economies that are involved in land administration rely on technology to drive their services. Technology enhances administrative efficiency through Web-enabling systems and egovernment. The United Nation Economic Commission for Europe UNECE - land Administration Guidelines (1996) defines land administration as "the process of recording and disseminating information about ownership, value and use of land when implementing land management policies". The essential feature of land as a commodity is the bundle of rights, restrictions and responsibilities that are attached to it. Commoditized rights in land are abstract which exist as ideas verified by the record base. Commoditization of land brought the role of cadastre to the front burner in land administration theory. The U.S National Research Council (NRC, 1980) in a study titled "the need for a multipurpose cadastre" advocated integrated cadastral survey and mapping functions through the use of geometric reference framework. This introduced possibility of effective cadastral system capable of multiple uses most especially in land tenure and value records. However, Cowen and Craig (2003) noted that the NRC vision was so idealistic and proved practically impossible to implement across Europe.

The modern European model of multipurpose cadastral was, however, developed by the International Federation of Surveyors with a focus on land information which represents "a parcel-based and up to-date land 
information system consisting of a record of interest in land (e.g rights, restriction and responsibilities" (FIG, 1995). It normally includes geometric description of land parcels linked to other records describing the nature of interest, ownership and often, the value of the parcels and its improvements. The need for a national approach to cadastral led the United State to commission a two-year NRC study titled 'Land Parcel Databases: A National Vision" (NRC, 2007). The study developed multipurpose cadastres as a fundamental land management tool with continental acceptance to the exclusion of those countries in Europe with private land registries.

In developing nations where there are lack of surveying and technical skills their cadastral construction relies in other options like aerial photos, satellite images, sketches combined with area maps. Cadastral developments in many nations are in continuum reflecting their different stages of evolution. It sometimes reflects nature, social, institutional, legal and economic circumstances of such nation. Besides, what makes multipurpose cadastral function is the spatial data infrastructure (SDI). It is the enabling platform for linking people to information. SDI supports integration of natural (Topographic) and built (Land parcel or cadastral) environment with environmental data as a basis for sustainable development.

In Nigeria, we are still struggling to develop rudimentary Land Administration System (LAS) to support integrated framework to aid decision makers in arriving at improved land administration. The application of Information and Communication Technology (ICT) to land administration was enhanced by engagement of spatial science and other businesses in the construction of land information products. This service is delivered through the internet and facilitated through inter-organizational workflows rooted in e-land administration which is the utilization of ICT capabilities to deliver land administration functions and services online.

\subsection{The electronic land management system}

Electronic land management is a recent development in Nigeria that was introduced by President Obasanjo after realizing the deficiencies of the manual system of record keeping on land matters. The president in 1999 directed that all land operations at the Federal level be computerized. This gave birth to Abuja Geographic Information Systems (AGIS) and Federal Land Information Systems (FELIS). The Federal Ministry of Housing and Urban Development is responsible for the management of all land belonging to the Federal Government of Nigeria in all the 36 states of the Federation while the Ministry of the Federal Capital Territory (MFCT), is only responsible for all land belonging to the Federal Government of Nigeria in the Federal Capital Territory, Abuja.

The AGIS has two components: Geographic Information Systems (GIS) and Land Information System (LIS). The GIS is the graphic aspect where all Cadastral information such as the Master plan, Land Use plans, detailed site development plans, engineering infrastructure and all survey information are captured and stored in digital form. The LIS constitutes the land attribute such as records of allocation (named allottes, plot numbers, plot size, uses and locations). It also includes records of all transaction such as power of attorney, deed of assignment, mortgages, sublease, releases, devolution and others.

The mission of the project is to provide a comprehensive, all inclusive foolproof and state of the art computerized geospatial data infrastructure for the Federal Capital Territory Abuja. The computerization of Federal Capital Territory Cadastral and land registry was in response to sanitize Land administration system in the Federal Capital Territory (FCT). Other programmes of AGIS include:

Faster updating and presentation of data (Spatial and Non-spatial)

Planning of revenue generation

Land acquisition and development

Existing Development and planning of new structures

Allocation of land for different uses like residential, commercial, industrial etc

Generation of reports for higher officials/management with adequate maps.

AGIS is building corporate spatial databases results to improve decision - making, operational efficiency, and to reduce duplication in the FCT. The AGIS is divided into three major components for efficiency namely: data capture and maintenance, system administration and development, and customer services.

The success recorded by AGIS and FELIS in Abuja have prompted Ondo state and other states of the federation to embark on land data captures and the development of their SDIs. Ondo State Land Record Bureau (LRB) was established in 2012 with the mandate to address the delay in land titling process and management. The bureau has recorded issuance of over 15,000 Certificate of Occupancy ( $\mathrm{C}$ of $\mathrm{O}$ ) for parcel of land; created a platform for online application and e-archived over 750,000 legacy land documents spanning over ten years. This Agency, in collaboration with the Presidential Technical Committee on Land Reform and UK Department for International Development GEMS-3 Programme has embarked on a flexible and cheap process of systematic land title registration in three pilot local government areas of the state. Currently, the LRB functions have been transferred to the Land Services Unit (LSU) of the Ministry of Land and Infrastructure (MLI) to avoid overlap of duties.

In the land market economy, the most critical activities for land administrators include how to monitor fluctuations in land prices, reveal behavior of property market, identify parcels of land which violate development 
standards, how to monitor dereliction, and environmental impact of any development. For better land management, land records need to be organized in a manner that will ensure synergies of information between various ministries and the public.

\subsection{Materials and Method}

Akure is a traditional Nigerian Yoruba city that situates in the South Western part of the country. It lies approximately on latitude $7^{0} 15^{\prime}$ North of the Equator and longitude $5^{0} 15^{\prime}$ East of the Greenwich Meridian (Macmillan, 2006). Akure is a medium- sized urban centre which became the provincial headquarters of Ondo province in 1939. It became both the capital city of Ondo State and Akure Local Government Council Headquarters in 1976. Consequently, the city has witnessed heterogeneous massing of people and activities.

The city's morphology has changed over time to assume its present status with its attendant housing problems, as experienced in similar medium sized urban centres in Nigeria. Akure is located approximately 420 kilometres South West of Abuja (the Federal Capital of Nigeria) and about 350 kilometres to Lagos (the former capital of Nigeria). It is located within the tropical rain forest region of Nigeria where rainfall is high throughout the year. The climate is hot and humid, influenced by rain-bearing southwest monsoon winds from the ocean and dry northwest winds from the Sahara Desert. The rainy season lasts from April to October, with rainfall of about $1524 \mathrm{~mm}$ per year. The rainfall distribution is characterized by marked dry season of about three months from November to January (Olatunji, 2007). Temperatures vary from $28^{\circ} \mathrm{C}$ to $31^{\circ} \mathrm{C}$ with mean annual relative humidity of about $80 \%$ (Nigerian Metrological Agencies, 2012).

The population of the city grew from 38,852 in 1952 to 71,106 in 1963 . Its population was estimated to be 112,850 in 1980 and 157,947 in 1990 (Ondo State Government, 1990). The 1991 national population census put the population of Akure at 239,124 and its estimates for 1996 was 269,207 (NPC, 1996). According to the 2006 National Population Census, the population of Akure was 360, 268. This was projected to 2014 using 3.2\% growth rate. Presently, the population is 457, 095 inhabitant. Akure as a city is currently experiencing housing challenge, particularly in the area of residential density mix which may transform to a major problem in the foreseeable future as the city population continues to grow.

The data for the research was generated from both primary and secondary sources. Primary data were generated from the administration of structured questionnaire that captured information on socio-economic characteristics of the respondents, location of buildings, plot sizes, coverage and prices among others. The questionnaires were administered to the household heads in selected residential buildings in the study area. Secondary data were obtained from Ondo State Ministries of Physical Planning and Urban Development, Lands and Infrastructure and Development and Property Corporation, Akure, while building population were obtained from the National Population Commission (NPC) and google maps.

The study examined the three residential zones in Akure which are the core; transitional and periphery, and looked into the distribution of housing densities within the zones. It equally considered the housing densities types and location of residents in relation to their land pricing profile. The pattern of residential development in Akure was completely covered as one residential estate was selected from each residential zone. These were Oke-Ogba Estate along Agagu Road, Obele Estate along Ijare Road and Ademola Adesida Estate in Alagbaka all located in the core (high density), transitional (medium density) and periphery (low density) of the city respectively. The estates were chosen in the sample survey because of their peculiar characteristics with the other estates along their corridors.

The enumeration areas for the study were determined with the use of google maps of the three residential estates which showed the total buildings in each. Grid method was employed to divide each map into equal squares, thus, making it possible to count the buildings with the aid of GIS and IKONOS Imagery which put the estimates in Oke Ogba at 2,723; Obele, 2,117 and Alagbaka, 264. Ten percent (10\%) of the total number of buildings on each of the maps constituted the sample size for study, resulting in 272, 212 and 26 buildings for Oke Ogba, Obele and Alagbaka housing estates respectively. The random number generator in the Graph Pad Software was used to select the grids. This Graph Pad Software (Quick Calcs) is scientific software that was used to create a table of random numbers employed in the selection of the research samples. Generally, descriptive and inferential statistics such as Chi-squared ( $X^{2}$ ), Student T-Test, and regression techniques were employed in data processing with the help of the Statistical Package for Social Sciences (SPSS) version 21 while graphs and tables were used to illustrate research findings.

\subsection{Findings}

\subsection{Price of plot and household size}

Cross tabulation data between price of plot and household size of the respondents in Akure revealed some valuable information. Standard household sizes indicate that 1-3 household size represents a low-density plot; 4-7 represents a medium density plot; while more than 7 is a typical high-density plot. Results from the price in relation to household size for the various densities indicated that for a high density price, the medium density household size 
was about half (49\%) of the residents in that category out of about $80 \%$ that made up the category. For the medium density price, the medium household size was highest $(9 \%)$ out of $16.5 \%$ in that category. The low-density price recorded the lowest $(3.9 \%)$. In this density category, the household size for medium density was prevalent. The results obtained also revealed that across the price density categories, the medium household size still recorded the highest $(60.2 \%)$ relative to other household size categories. It can, therefore, be inferred that in the study area, the mix of price with household size was of ratio 0.9: 6:3.1 across the price densities, hence, the medium household size in relation to price is the most significant.

The result of the correlation analysis between price of plot and household size in table 1 revealed a significantly weak inverse relationship $(\mathrm{P} \leq 0.05)$. However, it can be inferred that there are more factors that will enhance price of land in the study area apart from the household size These factors may include location, proximity and availability of social amenities, personal desires and interests among others.

Table 1: Relationship between land price and household size

\begin{tabular}{llcc}
\hline \multirow{2}{*}{ Price } & Correlation Coefficient & Price & Household Size \\
& Sig. (2-tailed) & 1.000 & $-.098^{*}$ \\
Household Size & Correlation Coefficient & -.000 \\
& Sig. (2-tailed) & $.098^{*}$ & 1.000 \\
\hline
\end{tabular}

* Correlation is significant at the 0.05 level (2-tailed).

\subsection{Price of plot and income}

Findings revealed the income categories of residents as below N200, 000 (\$555.6) in a high density plot; N201,000 - N300,000 (\$558.3 - \$833.3)in a medium density plot; and above N300,000 (\$833.3) in a low-density plot. Results indicated that for a high density price, the high density income residents were dominant $(54.5 \%)$ out of the $79.6 \%$ making up that category. In the medium density price of $16.5 \%$, the high density income residents had the highest percentage $(9.4 \%)$. The low-density price accounted for the lowest percentage $(3.9 \%)$, while medium density income residents were highest.

The results obtained also revealed that across the price density categories, the high density income group recorded the highest $(65.5 \%)$ relative to other income categories. Generally in the study area, the ratio of mix of price with income is 65.5: 33.7:0.8 across the price densities, thus, making the high density income in relation to price the most significant.

The result of relationship between price of plot and income level of residents in table 2 revealed a significantly weak positive relationship with a coefficient of correlation of $0.161, \mathrm{P}<0.01$ in the residential estates.

Table 2: Relationship between price of plot and income of respondents

\begin{tabular}{llcc}
\hline & & Price & Income \\
\hline Price & Correlation Coefficient & 1.000 & $.161^{* *}$ \\
& Sig. (2-tailed) &. & .000 \\
Income & Correlation Coefficient & $.161^{* *}$ & 1.000 \\
& Sig. (2-tailed) & .000 &. \\
\hline
\end{tabular}

** Correlation is significant at the 0.01 level (2-tailed).

\subsection{Price of plot and land area}

Results of cross tabulation between price of plot and land area occupied by residents showed some interesting information. A standard land area of $648 \mathrm{~m}^{2}$ represents a high-density plot; $864 \mathrm{~m}^{2}$, a medium density plot, and $1080 \mathrm{~m}^{2}$, a low-density plot. The price of plot in relation to land area for various densities considered for a high density price revealed that, the high density accounted for $76.5 \%$ of the $79.6 \%$ in that category. In the area of medium density price, the high density plot has the highest amount percentage $(14.3 \%)$ out of the $16.5 \%$ in that category. Surprisingly, the high density land still dominates $(3.7 \%)$ the low-density price area that accounted for just $3.9 \%$. In this density category, the low density plot is scarce. The results obtained also revealed that across the price density categories, the high density plot recorded the highest proportion $(94.5 \%)$ relative to other land area categories. It can be construed, therefore, that in the city, the ratio of mix of price with land area is 94.5: 5.3:0.2 across the price densities, where the high density plot area is the most significant.

The result of the correlation analysis between price of plot and land area in table 3 , revealed a significantly weak inverse relationship, with a coefficient of correlation of $-0.098, \mathrm{P}<0.05$. The implication of this is that other factors such as the topography of the land, accessibility of the land and geology of the land may influence the price of plot in Akure. 
Table 3: Relationship between price of plot and land area

\begin{tabular}{llcc}
\hline & & Price & Land Area \\
\hline Price & Correlation Coefficient & 1.000 & $-.098^{*}$ \\
& Sig. (2-tailed) &. & .000 \\
Land Area & Correlation Coefficient & $-.098^{*}$ & 1.000 \\
& Sig. (2-tailed) & .000 &. \\
\hline
\end{tabular}

* Correlation is significant at the 0.05 level (2-tailed).

\subsection{Development of e-Land Pricing System}

The study developed an electronic evaluation model for land pricing in Akure using Oke-Ogba, Orita-Obele and Alagbaka as case studies in the high, medium and low density regions respectively. The factors that are mainly responsible for land pricing as derived from literature include household size, income, distance from city centre, plot area, year of purchase, number of persons per building, number of buildings per plot and number of families per plot. These factors were used as predictors of land price in this research.

Household size which defines the number of persons that live in the same dwelling and share meals was determined across the 3 densities. Households of 1 to 3 persons were found in low density; 4 to 7 persons, in middle density and above 7 in high density regions. The significant role of income in the housing market dynamics was acknowledge because people with high income will be able to purchase expensive land in choice areas unlike their low-income counterparts. Research findings had revealed that the high income earners tend to live in low density areas and vice-versa for the low-income earners. However, an increase in income of residents might be responsible for the willingness to purchase land at high prices.

Distance from city centre showed that prospective land buyers will prefer to purchase land in regions that are not too far from the city centre. Indeed, the farther the plot of land from the city centre, the less attractive it becomes to the buyer. Plot area was critical in the model evaluation. The standard plot size was $648 \mathrm{~m}^{2}$ otherwise referred to as high density plot. The second category was the medium density plot of $864 \mathrm{~m}^{2}$, and lastly the low density plot area of $1080 \mathrm{~m}^{2}$. The plot size required by prospective land buyer, often determined the amount that would be paid. Generally, the low density plots were more expensive than the middle and high density plots. Year of purchase was also a great determinant of land price because the farther the year, the lower the price of land, unlike in the recent years when prices of land were high.

Number of persons per building was another important variable that determined land price in the city. Higher number of persons per building suggests a high density zone which might not be attractive to high income earners who prefer a quieter environment. The number of buildings per plot as a factor envisages more buildings in a high density zone where it plays a crucial role in determining land prices. This is closely connected with the number of families per plot as more families on a plot also result in high density.

These variables form the independent variables that determine land prices in Akure, while land price represents the dependent variable. Regression analysis was employed to model the contribution of each variable when other variables are held constant. The highest observed correlation is less than $0.80-$ an indication that collinearity or multi-collinearity does not exist among the variables. This, therefore, confirms the true independence and reliability of the variables and parameter estimates used in this analysis. The regression model is, therefore, expressed as follows:

$\mathrm{Y}($ LandPrice $)=\mathrm{b}_{0}+\mathrm{b}_{1}($ Household_Size $)+\mathrm{b}_{2}($ Income $)+\mathrm{b}_{3}($ Distance $)+\mathrm{b}_{4}($ PlotArea $)+\mathrm{b}_{5}($ Year_Purchase $)+$ $\mathrm{b}_{6}($ Persons_Building $)+\mathrm{b}_{7}($ Buildings_Plot $)+\mathrm{b}_{8}($ Family_Plot $)+\mathrm{e}$

Table 4: Regression analysis of e-land pricing variables

Coefficients

Model

1 (Constant)

hhsize_rec

income_rec

distance_rec

plotarea_rec

noperson_rec

nobldgperplot_rec

familyperplot_rec

yearpurchase rec

Unstandardized Coefficients
B

1.833

0.094

0.114

$-0.556$

0.194

$-0.030$

$-0.018$

0.006

0.229

Dependent Variable: Land Price (buyplot rec)

0.769

0.041

0.045

0.250

0.092

0.048

0.046

0.040

0.043
Standardized Coefficients

Beta

With household size variable, results revealed corresponding increase in land price by $9.4 \%$. In this study, a unit increase in household size is between 1 and 3 persons (i.e. when $\mathrm{X}_{1}=1$ ) to between 4 and 7 persons (i.e. when $\mathrm{X}_{1}=2$ ) A 2 -unit increase is between 1 and 3 
persons to above 7 persons (i.e. when $\mathrm{X}_{1}=3$ ) which will lead to a corresponding increase by $18.8 \%$ in land price. This could be true as land speculators can capitalize on this factor to increase land price in the area.

Income of land owners is critical in the determination of land prices. Low income earners are likely to purchase land where they are relatively cheap, hence, their willingness to purchase high density plots. Our analysis revealed that if all other variables are held constant, and there is a general increase in income of prospective buyers such that the lower income earner appreciating to the category of middle income earners (which we term here as a unit increase), then, the price of land will correspondingly increase by $11.4 \%$. If there is a 2 -unit increase, the land price will increase by $22.4 \%$. A general increase in fortunes will ensure that the housing market dynamics is affected, thus, prompting an increase by land speculators. Therefore, if a plot of land costs \#1,000,000 $(\$ 2,777.8)$, a general increase in income which could come about through many factors such as increase in minimum wage will trigger land prices to increase by $\$ 114,000$ ( $\$ 316.7$ ) thus, amounting to $\$ 1,114,000$ ( $\$ 3,094.4)$. A 2-unit increase would amount to $\$ 1,228,000(\$ 3,411.1)$ for the same plot of land.

Distance to city centre is a variable that was considered to be very important in this analysis. It was gathered from the fieldwork that some land buyers preferred to live close to the city centre while others did not. The classification was done in 3 categories. First, were areas with less than $1 \mathrm{~km}$, second, were areas between 1 and 6 $\mathrm{km}$, and the last were areas father than $6 \mathrm{~km}$ from the city centre. Holding all other variables constant, the model predicted that a unit increase in distance from the first category to the second will lead to a corresponding decrease in the willingness to pay for such plot of land at the specified price. Indeed, a unit increase will lead to $55.6 \%$ decrease in the land prices of such a plot and a 2-unit increase will ensure that land prices reduces by $111.2 \%$. Hence, if the land price in the first category is $\$ 1,000,000(\$ 2,777.8)$, then farther away to second category could mean a decrease in land price to $\$ 444,000$ (\$1,233.3). However, there are special cases, where the high income will prefer to live far away from the city centre (for example in Government Reservation Area - GRA where land prices are regulated), which will invariably play a significant role in determining the land price for such an area.

Plot Area/Size is a variable that assesses the effect the size of plot will have on land price. The standard plot size also known as high density plot is supposed to be cheapest; the medium density plot sizes are more expensive; the most expensive are the low density plot sizes which are normally purchased by high income earners. Regression analysis conducted indicated that if in a neighbourhood where the three density plots exist, a unit increase in plot size i.e. deciding to purchase a medium density plot rather than a high density plot, the land price will increase correspondingly by $19.4 \%$. Hence, if a high density plot values $\$ 1,000,000(\$ 2,777.8)$, a unit increase to a medium density plot size will be valued at $\$ 1,194,000$ (\$3,316.7), while a 2-unit increase to a low density plot will attract a value of $\$ 1,388,000(\$ 3,855.6)$.

Year of purchase is also an important land price determinant. As the available land becomes recent, the land price goes up, but the more distant it is to the present, the lower the land price. The three categories adopted for this study include land bought before 1990, land bought between 1990 and 2009, and land bought between 2010 till date. Results indicated a $22.9 \%$ increase between each of the periods. However, in reality, land prices have increased astronomically especially in the last 10 years in Akure being a state capital.

Results on number of persons per building revealed that as the number of persons living in a building increase by 1 , there is a corresponding decrease of land prices by $3 \%$ in such neighbourhood. The association with number of building per plot reveals that if residents in the neighbourhood decide to increase the number of buildings that occupy a plot of land probably for commercial or rental purposes, the neighbourhood will be viewed as a high density neighbourhood, hence, ensuring the reduction in value of land. Consequently, an increase in number of buildings per plot by 1 unit will lead to a corresponding decrease of land prices by $1.8 \%$ while a 2 -unit increase of buildings per plot will amount to a $3.6 \%$ decrease in land prices. This, thus, means that if a plot containing 1 building is valued at $\$ 1,000,000(\$ 2,777.8)$, increasing the number of buildings in the plot will ensure that land prices are reduced to $\$ 982,000(\$ 2,727.8)$ and with 2 buildings per plot, land price further reduces to $\$ 964,000$ $(\$ 2,677.7)$.

The number of family per plot had a minimal effect on land price. Results indicated that if number of families occupying a plot of land increases by 1 unit, then there will be a corresponding increase in land price by $0.6 \%$. This implies that if 1 family occupies a plot of land valued at N1,000,000 (\$2,777.8), then an increase to two families on the same plot moves the value up a bit to $\mathrm{N} 1,006,000(\$ 2,794.4)$.

\subsection{Recommendation and Conclusion}

Density arrangement is a topical issue in city development. The difference in prices of land has resulted in abnormal mix of densities culminating in unplanned residential districts in a fast-growing city like Akure. This research was carried out on ways of managing residential housing density in Akure, Nigeria through e-land pricing system. The research has identified certain factors such as distance, plot area and number of persons per building as major determinants of land price and housing density in the city requiring government planning intervention. Evident from this study is also the fact that both private (families) and government dispose land to housing developers, thus, leading to unregulated residential density mix. To address this trend, the Ondo State Government 
needs to put in place a strong framework for e-land pricing policy formulation and implementation.

Traditionally, public land administration is apparent in MLI and the Ministry of Physical Planning and Urban Development (MPPUD) as well as the Ondo State Development and Property Corporation (OSDPC). Those lands on which families lay claims are disposed privately. The study has, therefore, canvassed for a joint effort by both the land buyers and sellers including families and government. It is anticipated that the prospective land buyers, upon awareness will visit the Land Services Unit (LSU) portal of the Ministry of Land and Infrastructure (MLI) website and supply all relevant data for prediction of a suitable site. The list of neighbourhoods/layouts provided will guide choice making (site selection) and identification of the custodians of land at the core, transition and peripheral zones of the city. The procedure of searching for land axis on e-land price interface of LSU portal is as indicated in fig 1.

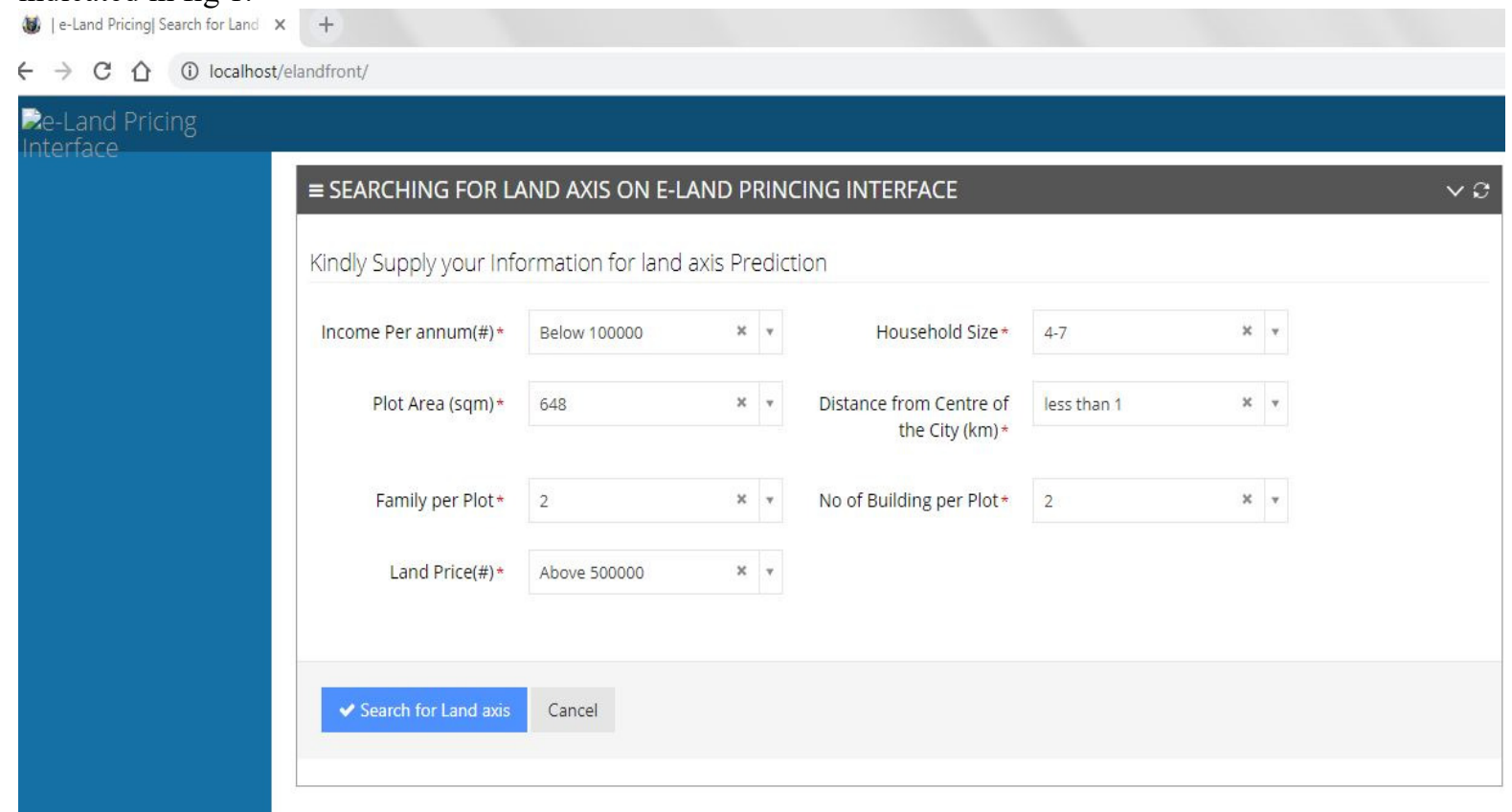

Figure 1: The e-Land Price Interface on LSU Portal

An administrative structure that can ensure management of the proposed e-land pricing reform measure is hereby suggested for effective density order in the city. With this structure, the MLI through its LSU should set a framework of Centralized Land Administrative System (CLAS) in which both private and public residential layouts will be co-ordinated for district planning and management of land acquisition. The SLU ensures registration of all residential layouts at the core, transition and periphery of the city and engages the landowners and relevant stakeholders in sensitization programmes on the e-land pricing initiative. Further efforts should be made to host an e-land pricing portal on MLI website to intending housing developers to consider land in specific densities that match their available capital.

The e-land pricing policy should be given wide publicity on the social media through advertisement to create the "entry point" awareness on land acquisition. Training programmes (workshops, seminars, etc) must be conducted regularly to remind the staff of their obligations in this regard. The MLI must also collaborate with the MPPUD, OSDPC and Ministry of Justice (MJ) and ensure that land owners and new developers comply with the policy and other practices that have significant impact on land administration in the city.

Under the new structure, the MLI stands as an autonomous entity like other civil service ministries, thus allowing staff mobilization, land price regulation and appropriate residential density arrangement in Akure. With the e-Land Pricing Model, the Ondo State Government will be able to provide well organized accommodation in Akure while granting priority attention to the density zones for a decent living.

\section{Acknowledgement}

The authors deeply acknowledge the sponsorship of the research by the Federal University of Technology, Akure through the TETFund Research Grant of the federal Government of Nigeria form which this article emerged.

\section{References}

Agbola, T. (2004): Readings in Urban and Regional Planning. Ibadan: Macmillan Nigeria Publishers Limited.

Agbola, T. and Olatubara, C.O. (2003): Private Sector Driven Housing Delivery (in Nigeria): Issues, Constraints, Challenges and Prospect. A Lead Paper Presented at the 2nd Annual National Workshop on Private Sector Driven Housing Delivery in Nigeria, University of Lagos, Lagos, 30th - 3rd July 
Aluko, O. (2010): The Effects of Location and Neighbourhoods Attributes on Housing Values in Metropolitan Lagos. Ethiopian Journal of Environmental Studies and Management, 4(2), 2011.http://dx.doi.org/10.4314/ejesm.v4i2.8

Cowen, D.J and Craig, W.J (2003). A Retrospective Look at the Need for a Multipurpose Cadastre. Surveying and Land Information Science 63(4):205-14.http://www.nationalcad.org/data/document/coulen_craig.pdf (Accessed May 12, 2009).

Duncan Bowie (2008) Housing Delivery and Sustainable Communities: London. Oxford University Press

Ebie, F. (2003): Greater Prospect Ahead in the Mortgage Sector. House and Property Magazine, 1(2), 43-49

Fasakin, J.O. (1998): Cooperative Housing; The Concept, Experience and applicability to Nigeria's socioeconomic millieu. Seminar paper presented at the Federal University of Technology, Akure.

FIG (1995). Statement on the Cadastre. FIG Publication No11 .FIG office. Copenhagen. http://www.fig.net/pub/figpub/pubindex.intm (Accessed May 12, 2010).

Ilechukwu, V., (2010): Land Values and Housing Densities in Nigerian Cities: The Case of Onitsha. Urban and Regional Planning Review, Department of Urban and Regional Planning, University of Lagos. 1 (3), 87-94

Jaiyeoba, B. and Amole, D. (2002): A Critique of Technology of Mass Housing. The City, Nigeria. Proceeding of Faculty of Environmental Design Conference, O. A. U., Ile-Ife 340-345

Lawanson, O. T. (2007): Poverty and Environmental Degradation in the Lagos Metropolis. Journal of Environmental Science. 11 (1), 36-65

Mabogunje, A. (2002): Housing Delivery Problems in Nigeria. Punch Newspaper, Wednesday, May, 2002.

Macmillan (2006): Beyond Scarcity: Power, Poverty and the Global Water Crisis. Human Development Report. United Nations Development Programme (UNDP).

Mehmet Topçu (2009) Accessibility Effect on Urban Land Value. Scientific Research and Essay. 4 (11), 12861291, http: //www.academic journals. org/ SREISSN 1992-2248

National Research Council (2007). Land Parcel Database: A National Vision: http://www8.nationalacademics.org/cp/projectview.aspx? Key=219. (Accessed May 12, 2010).

National Research Council (1980). Need for a Multipurpose Cadastre. Panel on Multipurpose cadastre. Committee on Geodesy Assembly of Mathematics and physical science. Washington,D.CNationalAcademypress.http://www.nap.edu/catalog.phy?record_id=10989 (Accessed May $12,2010)$.

Oduwaye, L (2009): Challenges of Sustainable Physical Planning and Development in Metropolitan Lagos. Journal of Sustainable Development. 2(1), pp. 159-171

Olatunji B. O. (2007): The Disgust Scale: Item Analysis, Factor Structure, and Suggestions for Refinement. Psychological Assessment, American Psychological Association. 19 (3), 281-286

Omirin, M. M., (1998): Land Accessibility and Low Income House Building. Journal of Environmental Studies 1, University of Lagos: Book Policy, Lagos

Omole F. K. and Akinbamijo O. B. (2012): Land Development and Planning Laws in Nigeria: The Historical Account. Journal of Law, Policy and Globalization. ISSN 2224-3240 (Paper) ISSN 2224-3259. 8. www.iiste.org

Omole F.K (2001): Basic issues in Housing Development. Akure; Femobless Publishers

Ondo State Government (1990). Digest of demographic Statistics of Ondo State. Ministry of Finance, Budget and Planning, Akure.

Onibokun, P. O, (1985): Housing Needs and Responses. A Planners' Viewpoint. In: Housing in Nigeria: A Book of Reading. NISER, Ibadan

UNECE (1996). Land Administration Guidelines with Special Reference to Countries in Transition. United Nation Economic Commission for Europe. New York and Geneva. Switzerland. http://www.unece.org/h/m/wpla/publications/laguidelines (Accessed August 1, 2009).

Williams, G. (2002): Home Ownership for the Urban Poor. Journal of Environment Studies 2(2), 103-114 